\title{
Harnessing Indigenous Technical Knowledge for Pest Management in Pea Crop
}

\author{
Neha Makol ${ }^{1}$, Dr. Puja Gupta ${ }^{2}$
}

\author{
${ }^{1}$ Department of Resource Management and Design Application, Lady Irwin College, University of Delh, New Delhi, India \\ ${ }^{2}$ Assistant Professor, Department of Resource Management and Design Application, Lady Irwin College, University of Delhi \\ New Delhi, India
}

\begin{abstract}
India's rich bio-diversity is an ace factor, always providing a wide source of biopesticides which can be effectively used in agriculture at a large scale. Also increasing health consciousness of Indian citizens has created a demand of organic food. The rich indigenous technical knowledge base available with the highly diverse indigenous communities in India provide valuable clues for developing and innovating newer and effective biopesticides. Pea is one of the off-season vegetable grown in the villages in the ecozone of Great Himalayan National Park. The farmers are completely dependent on chemical pesticides for pest management in pea crop. The use of biopesticides can reduce the dependence on chemical pesticides and it will further reduce its harmful effects on consumers and environment. This indicates huge scope for growth of biopesticides sector.
\end{abstract}

Keywords-Chemical Pesticides, Efficacy, Indigenous Technical Knowledge (ITK), Pea, Potential biopesticide (PBP).

\section{INTRODUCTION}

Pesticides were being widely used during the green revolution and consumption of pesticides is increasing thereafter. Pesticides have numerous beneficial effects. These include crop protection, preservation of food and materials and prevention of vector-borne diseases. Although there are benefits to the use of pesticides, some also have drawbacks, such as potential toxicity to humans and other animals. The ill-effects may follow from shortor long-term exposure and from low- or high-level exposure through skin contact, inhalation, or ingestion. Some pesticides are highly toxic, with a few drops causing extremely harmful effects; although other pesticides are less toxic, too much exposure to them can also cause harmful effects (Gupta, 2004). So, there is growing concern about human exposure to pesticides and harmful effects on health.

According to a survey conducted by the International Crops Research Institute for the Semi-Arid Tropics (ICRISAT), 93\% of Indian farmers use only chemicals to control insect pests and crops receive between 1-15 pesticide sprays prior to harvest. Despite the heavy use of pesticides farmers still lose $11-40 \%$ of their crop due to pest damage. Pesticide overuse has other non-economic side effects as well. Frequent sprays lead to insecticide resistance, thereby decreasing the efficacy of pesticides. Pesticides also kill insect natural enemies. Reduction in the natural enemy populations can allow minor pest populations to explode, leading to secondary pest outbreaks. The Indian government has banned the use of a number of pesticides for use in agriculture including DDT and BHC, however government policies are not being strictly enforced so many of these pesticides are still widely used in agriculture. Additionally most Indian farmers do not wear protective clothing or use proper spray equipment and do not understand how to properly use and apply pesticides (Kumar P., 2012).

At present, India is the third largest producer of pesticides in Asia and ranks twelfth in the world for the use of pesticides with an annual production of 90,000 tonnes. The consumption is $381 \mathrm{~g}$ when compared to world average of $500 \mathrm{~g}$. The pesticide consumption in India is limited to about $25 \%$ of the arable land. A vast majority of the population in India (56.7\%) is engaged in agriculture and is therefore exposed to the pesticides used in agriculture (GOI, 2002). Pesticide production and use in the country shows a different pattern from global trends - insecticide use is around $75 \%$ in the country, compared to $32 \%$ in the world. Herbicide use is only $12 \%$ in the country while worldwide consumption is $47 \%$. Similarly, while carbamate and synthetic pyrethroid compounds are used the most globally (45\% together), in India, organophosphates constitute $50 \%$ of the consumption. Similarly, biopesticides are used only up to $2.89 \%$ amongst all pesticides in India, while worldwide, it is 12\% (Gupta, 2004).

In the process of development of agriculture, pesticides have become an important tool as a plant protection agent for boosting food production. Further, pesticides play a significant role by keeping many dreadful diseases. However, exposure to pesticides both occupationally and environmentally causes a range of human health problems. A vast majority of the population in India is 
engaged in agriculture and is therefore exposed to the pesticides used in agriculture. Although Indian average consumption of pesticide is far lower than many other developed economies, the problem of pesticide residue is very high in India. Pesticide residue in several crops has also affected the export of agricultural commodities in the last few years. In this context, pesticide safety, regulation of pesticide use, proper application technologies, and integrated pest management are some of the key strategies for minimizing human exposure to pesticides (Abhilash, 2009).

Peas are highly nutritive and contain high content of digestible protein $(7.2 \mathrm{~g} / 100 \mathrm{~g})$, Carbohydrate (15.8 g), Vitamin-C (9 mg), phosphorus (139 mg) and minerals. Canned, frozen and dehydrated peas are very common for use during off-season. Like any legume crop, pea is an integral component of sustainable agriculture due to its soil enriching and conditioning properties (T THOMSON, 2015 ).

Agriculture in Himachal Pradesh has traversed a long way during the past four decades. The growing unviability of landholdings, almost stagnant productivity of traditional crops, livelihood security concerns, increasing incomes, changing consumption patterns and availability of newer technological options have tempted the farmers to shift to new crops in the state. Earlier, the commercial cultivation of vegetable crops was confined to selected pockets in the mid and high hills of the state. However, the vegetable based agricultural diversification has expanded to new areas in the low and mid hills after the early 1990s. This has unleashed a revolution in the production of vegetables in the state. Many new developments such as protected cultivation, emphasis on micro irrigation, organic agriculture and cultivation of more lucrative crops have added new dimensions to the agriculture in the state. The state produces a variety of vegetable crops, yet the pea (green), potato, tomato, cabbage, cauliflower, garlic and ginger occupy more area than the other vegetable crops (Kumar D. V., Estimation of cost of cultivation of commercial crops in Himachal Pradesh, 2013). The cultivation of pea crop occupies the largest share which is approximately $30 \%$ in terms of area and production in Himachal Pradesh. In India, it occupies an area of 313.5 thousand hectares with a production of 25.6 lakh tons, whereas, in Himachal Pradesh pea is grown in an area of 17,400 ha with a production of 2,03,000 metric tons bulk of which is produced during the summer season (Board, 2011). Pest damage is one of the major constraints in realisation of attainable yield of peas. Peas are susceptible to pea weevils, pea aphid, leaf miner and pod borer which are the major pests and wilt and root-rot, powdery mildew, rust, Ascochyta blight and pod rot are major diseases of pea (K. G. Mukerji Rajeev H. Upadhyay).
This study with the objective of using indigenous technical knowledge for developing a potential biopesticide will be another step towards sustainable agriculture which will help farmers to shift to safer pest management practices.

\subsection{Objectives}

The present study on "Harnessing Indigenous Technical Knowledge for Pest Management in Pea Crop" was carried out while focussing on following objectives:

- To augment the existing awareness, perceived challenges, practices followed by the farmers with respect to pesticide usage for pea crop.

- To develop a potential biopesticide using ITK (Indigenous technical knowledge) and compare its efficacy with chemical pesticide being used by the sample with respect to soil $\mathrm{pH}$ levels, crop yield and cost benefit ratio.

- To promote the usage of safer and environmentfriendly pest management practices.

\section{MATERIALS AND METHOD}

The research "Harnessing Indigenous Technical knowledge for Pest Management in Pea crop" was aimed to develop a potential biopesticide using ITK for pest management in pea crop. The study was carried out in following three phases:

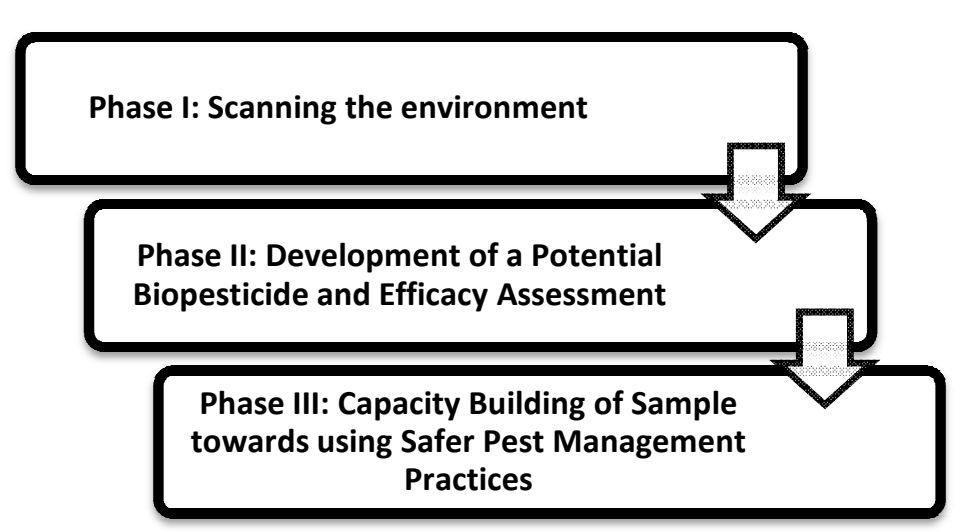

Phase I: Scanning of the Environment

Sampling: Pea crop growing farmers represented the sample for this phase. For selecting the sample, a list of all pea crop growing farmers was prepared. From the list, 30 farmers were randomly selected.

The data was collected regarding the existing awareness of the farmers and the practices they follow for pesticide use using pre-intervention tool and observations. The preintervention tool was an interview schedule. The data was analysed using statistical software MS Excel.

Phase II: Development of a Potential Biopesticide and Efficacy Assessment

The potential biopesticide was developed using stinging nettle leaves and garlic and the field experimentation was 
carried out in the agricultural field of a farmer during rabi season. The experiment was laid out in a generalised randomized block design (G.R.B.D.) with three treatments including treatment with chemical pesticides, potential biopesticide and untreated control plots with three replicates of each. The efficacy of treatments was assessed on the basis of $\mathrm{pH}$ of the soil; crop yield and cost benefit ratio and beneficiaries perspective.

The data was collected using experimentation tools which were $\mathrm{pH}$ detecting kit, observations and checklist. The data was analysed using statistical software like MS excel and SPSS

Phase III: Capacity Building of Sample towards using Safer Pest Management Practices

Sampling: Pea crop growing farmers represented the sample for this phase. For selecting the sample, a list of all pea crop growing farmers was prepared. From the list, 30 farmers were randomly selected to be a part of the capacity building program.

The data was collected using post-intervention tool. The post-intervention tool was an interview schedule. The data was analysed using statistical software MS Excel.

\subsection{STUDY AREA}

The study was conducted in Pekhri situated in the ecozone of Great Himalayan National Park. Pekhri is a small hamlet in Banjar Tehsil in Kullu district of Himachal Pradesh state, India and Pea is the second largest vegetable crop grown in this area they also enjoy the price advantage due to off-seasonal nature of this crop in this area (Kumar, 2013).

\section{RESULTS AND DISCUSSIONS}

The present study entitles "Harnessing Indigenous Technical Knowledge for Pest Management in Pea Crop" was carried out to gain an insight about the agricultural practices followed by the farmers regarding pesticide use. This study aimed to promote the use of ITK and safe and judicious use of chemical pesticides. The findings of this study have been studied under heads, consistent with the objectives of this study:

\subsection{Assessment of the existing situation}

\subsubsection{Profile of the respondents}

In the present study, 30 farmers were interviewed to gather information about the practices that they followed for pesticide use.

There was a high proportion of males (90\%) than females (10\%) which can be ascribed to the fact that the most of the activities related to pesticides like buying, spraying were performed by males.

The respondents included nearly half of the sample belonging to age group 20-39 and also young farmers with age below 20 years indicating a huge potential for seeking benefits of PBP and knowledge regarding pesticides.

Nearly half of the sample completed their schooling till $10^{\text {th }}$ class and while some respondents $(30 \%)$ completed their senior secondary education. The findings inferred that respondents above 50 years constituted $23 \%$ of the sample who didn't receive formal schooling.

\subsubsection{Agriculture related information}

Most of the respondents (47\%) held 11-20 bigha area of land where $40 \%$ of the respondents owned 1-10 bighas of land. Only few respondents $(13 \%)$ had huge areas of land under their ownership.

The chief food crops like wheat, maize, pea and garlic were mostly cultivated by the sample in the locale around the year. Other off season vegetables like French beans, tomato and cauliflower were also cultivated by the sample which was according to their land possession. The researcher observed that most of the crops cultivated by the sample were initially used to fulfil their family needs and the left of the yield was sold in the markets.

Nearly half of the respondents $(40 \%)$ had $10-15$ years of experience in agriculture and also $23 \%$ of respondents had more than 15 years of experience. It was found from the respondents that at a very early age, they were sent to the fields to learn agricultural practices and despite of their educational qualifications, all the residents living in the locale had to work in their agricultural field which was also observed by the researcher.

Two-third of the respondents didn't know about the ITKs and had never practiced them for pest management whereas only one-third of the sample which constituted the respondents with vast experience in agriculture had used bio-products for pest control.

ITK based products mostly used by the sample was cow urine and tobacco which was used to control pests in cabbage, pea, mustard whereas chulah ash was the second most used ITK by the sample to control chewing and sucking type of insects. Very few respondents had used nettle leaves for pest control despite of its huge availability in the locale.

3.2.3 Problem of pest infestation, frequency and methods followed for pea crop

All the respondents in the locale faced the problem of pest infestation and majority of the sample (73\%) faced the problem more than once in each crop season whereas 27 $\%$ of the sample faced it only once. As it was observed that the problem of pest infestation was more common in the flowering season.

The most common pea problem was aphids (60\%) faced by the sample. Pod borers are also a common pest of pea. This pest had become very serious in North India (Sharma, 2013). Thus it was a common pest faced by the sample in pea crop. Powdery mildew is a disease, least 
faced by the sample. It was observed by the researcher that the varieties of pea available to the sample were mostly immune to powdery mildew and hence it was not a very common problem faced by the sample.

Exact two-third of the sample $(67 \%)$ were unaware about biopesticides and had never heard of them while few respondents (33\%) had knowledge about biopesticides and how plant extracts are used to develop biopesticides which is safer and environmentally safer option of pest management.

All the respondents used pesticides to manage pest infestation and all of them $(100 \%)$ were dependent on chemical pesticides for pest management in crops. The respondents who were aware about biopesticides gave unavailability in the market as the reason for never using biopesticides for pest management and rest other respondents were unaware about the option of biopesticides, hence never used them in their crops.

The chemical pesticides were effective for pest management according to majority of the sample and also procuring chemical pesticides was easy for them due to their easy availability in the markets and subsidies provided by the government while only few respondents felt that chemical pesticides were not an effective option as they had faced crop loss despite of the use of chemical pesticide which could also be reasoned out to inadequate dosage, poor irrigation, seed variety or some other abiotic factors.

Inference was drawn from the findings that about half of the sample $(50 \%)$ was unsure about using the biopesticide as they were not certain about the effectiveness of a new pesticide and using a new pesticide may result in poor pest control and thus crop failure. However if proven effective, they would definitely try it for their crop protection. (20\%) of the sample were very positive about trying a new biopesticide which will be a user friendly and an environmentally safer option whereas $30 \%$ of the sample were not willing to shift to biopesticides which was reasoned out to good efficacy of chemical pesticides for pest management and its easy availability.

\subsubsection{Knowledge about safe and judicious use of} pesticides

The findings showed that one third of the sample $33 \%$ received information from the retailers and equal percentage of respondents found their neighbours, as a trusted source of information and used the same kind of pesticide that their neighbours used for their crops. Also $16 \%$ of the respondents had got the knowledge from the government consultants. Rest of the respondents received information and training from kisan seva Kendra (centres to provide help to farmers), kisan mela (fairs organised for farmers) and agriculture divisions.
Most of the respondents used the whole $250 \mathrm{~mL}$ bottle for an area of 1 bigha (1bigha $=8$ acres) and while few $33 \%$ of the respondents used only $150-200 \mathrm{~mL}$ of dose for an area of 1 bigha which was the recommended dosage to be used as per written on the bottle of the chemical pesticide used mostly by the sample. This alludes to the fact that usage of pesticides by sample was not in the right quantities. As per researcher's observations, people used extra dose of pesticides than recommended as they felt that it would lead to better plant protection from pests.

According to the findings, majority of the sample followed the measures like long sleeve shirts, full pants, gloves and boots to avoid contact with the chemical spray, although these equipments were not waterproof. But the respondents didn't follow the right kind of protective measures for covering their faces, most of them used handkerchief which didn't give full coverage of their faces and yet it was not a permanent solution. Most of the respondents didn't use proper protective equipment as they were expensive to buy and they didn't feel the need to follow these measures.

The most commonly used method of applying pesticides is sprayers like handy sprayers, knapsack sprayers which was used by $93 \%$ of sample whereas minority of the sample $(7 \%)$ who owned large area of farming land used big spraying machines. The same was also observed by the researcher during her visit to the agricultural fields.

Majority of the respondents $(93 \%)$ used the original containers or the same packaging of the pesticides to store the pesticides. Only $7 \%$ of sample used their own containers as they shift the pesticides to smaller containers after some use to avoid storing big containers of pesticides.

The findings inferred that most of the respondents $(60 \%)$ were aware that the pesticides should not be kept in the house; hence they kept the containers in the storage area. This data infers that majority of the respondents had knowledge about keeping the pesticides out of reach of the children. Whereas few respondents $(26 \%)$ kept it near their farming fields and others (14\%) kept the containers outside the house where the pesticides were accessible to stray animals and children.

The containers/bottles of the pesticides were burnt by 60 $\%$ of the sample whereas $33 \%$ of respondents buried the containers in barren land which was the mostly suggested method of disposing off the containers which included the plastics, cardboard and paper. Only $7 \%$ of respondents threw the containers in open fields which inferred that the containers were not being disposed off in the correct manner. 


\subsubsection{Harmful effects of chemical pesticides faced by sample}

The most common health problem faced by the sample was headache and dizziness during the spray of pesticides. Also they felt irritation in their nose due to the strong smell of the chemical pesticides and faced a problem in breathing which was more common among people who did not use proper respirators instead they used handkerchief to cover their mouths.

The fertility of the soil had got impacted over the years due to the use of pesticides in their fields was felt by majority of the sample, whereas small proportion of people had not experienced any change in their soil fertility. The respondents had got the facility of getting their soil checked in the government approved laboratories to get information about the soil and its health. According to the respondents, the soil fertility had got impacted in terms of the yield obtained which had reduced over the years; hence they were dependent on different types of high yielding varieties of seeds which were expensive to buy.

\subsection{Efficacy assessment}

Efficacy was assessed from the plots arranged in G.R.B.D. applied with three treatments which were potential biopesticide (PBP), chemical pesticide (CP) and control were calculated and discussed for following parameters:

- $\mathrm{pH}$ of soil: The pesticide sprays didn't affect the $\mathrm{pH}$ of the soil which can be ascribed to the fact that the soils in wet temperate zones of Himachal Pradesh are more acidic ( $\mathrm{pH} 5.2$ to 6.8) which might be due to more leaching of bases because of high precipitation (Himachal Journal of Agricultural Research). Therefore the location of the locale being in high hills and sub temperature zones at an elevation of $2150 \mathrm{~m}$ above sea level can be the reason for the acidic $\mathrm{pH}$ of the soil.

- Corrected \% pod damage reduction over control: The inference drawn through efficacy tests is that the chemical pesticides were higher in effectiveness as they resulted in reduction of $93 \%$ less pod damage over control plots, whereas the use of potential biopesticides resulted in reduction of $54.6 \%$ pod damage. The result of t-test verifies statistically significant difference for corrected $\%$ pod damage reduction over control between chemical pesticide and potential biopesticide.

- Yield: The mean of the yield of the plots treated with chemical pesticide (1.55) was comparatively higher than the plots given potential biopesticide (1.27). Thus this can be inferred that due to higher efficacy of the chemical pesticide in terms of corrected $\%$ pod damage reduction, the yield obtained was more in weight. The result of t-test shows that there is a statistically significant difference in the yield between chemical pesticide treated and potential biopesticide treated plots.

- Cost benefit ratio: The cost benefit ratio was higher for the plots treated with PBP $(0.87)$ which is higher than the ratio obtained by the plots treated with chemical pesticide (0.857). The cost incurred for pest management through chemical pesticide was very high in comparison to the cost realised for procuring potential biopesticide.

- Beneficiaries Perspective: The criterion like better quality, ease of handling, low cost, and no harmful effects on health and environment were major reasons for which the potential biopesticide were preferred over chemical pesticides by beneficiaries of this study.

\subsection{Appraisal of sample's experience of the capacity building program}

Most of the respondents (60\%) found the whole experience of capacity building program good and informative. They were quite enthusiastic to know the process of developing the potential biopesticide while few respondents (37\%) found the session to be average and satisfactory. Majority of the respondents appreciated the delivery and content of the program.

Nearly half of the sample (47\%) understood the whole process of developing the potential biopesticide and they would be able to develop it at individual level for their own use while $40 \%$ of the sample had some ambiguity about the process which was cleared by the researcher. Pamphlets were also distributed to reinforce the knowledge regarding the process and it would also help the respondents (14\%) who did not understand the process well to develop it.

Most of the respondents (67\%) were willing to use the potential biopesticide. There were also some respondents (27\%) who were unsure about the use of potential biopesticide as they would use it once their neighbours experience good results from its use. Word of mouth might also change the unwilling respondents' (6\%) opinion about not using it.

All the respondents (100\%) understood the importance of right dosage, protective clothing, proper storage and handling of chemical pesticides. In phase 1 of this study, it was analyzed that most of the respondents didn't follow the measures to be taken regarding personal protective proper clothing and hence they experienced health issues while spraying, therefore it was imperative to impart knowledge to them about safe and judicious use of pesticides. 
Chemical pesticides were preferred by $66 \%$ of the sample due to their high effectiveness and easy accessibility. But after the capacity building program $33 \%$ of the respondents were willing to adopt the use of biopesticides for pest management.

After the capacity building program, all the respondents were willing to be a part of such program. They found such programs very useful and informative as they helped them to improve their agricultural practices and they would recommend it to other villagers.

\section{CONCLUSION}

Thus the study connotes that PBP was proved better because it is an eco-friendly material, cheap, safe to the natural enemies, human beings, and environment as it is obtained by using plant extracts and its application on crops resulted in economical and sustainable yields. The study connotes that potential biopesticide can bring a change in the present pattern of use of chemical pesticides by the farmers. The PBP can be used in regions with similar geographical conditions for effective pest management. The study will be shared with agricultural research institutes for its effective usage.

\section{REFERENCES}

[1] Abhilash, P. S. (2009). Pesticide use and apllication: An Indian Scenario. Uttar Pradesh.

[2] Board, N. H. (2011). National Horticulture Database.

[3] GOI. (2002). Tenth Fiver Year Plan (2002-07). 513566.

[4] Gupta, P. (2004). Pesticide exposure-Indian scene. Toxicology in the New Century, Opportunities and Challenges - Proceedings of the 5th Congress of Toxicology in Developing Countries , 83-90.

[5] Himachal Journal of Agricultural Research. (n.d.). 80-85.

[6] K. G. Mukerji Rajeev H. Upadhyay, O. B. Integrated pest and disease mangement .

[7] Kumar, D. V. (2013). Estimation of cost of cultivation of commercial crops in Himachal Pradesh. Palampur.

[8] Kumar, P. (2012). Feeding the future: Crop protection today. Varanasi: Sadguru Publications.

[9] Sharma, B. B. (2013, April 25). Organic Production of Garden Pea. Krishi Sewa .

[10]T THOMSON, G. P. (2015). Effect of plant growth substances and antioxidants on growth, flowering, yield, and economics of garden pea, Pisum Sativum $\mathrm{L}$ cv Bonneville. International Journal of Farm Sciences , 8-13. 